\title{
A EXPERIÊNCIA EM ENCOSTAS OCUPADAS DO RECIFE: INTEGRAÇÃO TÉCNICA, INSTITUCIONAL E COMUNITÁRIA
}

\author{
Jaime de Azevedo GUSMÃO FILHO
}

\begin{abstract}
RESUMO
O trabalho dá um quadro geral do ambiente físico do Recife e mostra como a carta geotécnica pode contribuir para a solução dos inúmeros problemas da cidade. $\mathrm{O}$ mais sério deles, hoje, é o geológico de deslizamento, durante o inverno, que atinge as encostas ocupadas. A experiência de uma ação integrada, do ponto de vista técnico, institucional e comunitário, mostrou pleno êxito.
\end{abstract}

\section{ABSTRACT}

This paper gives an overview of the physical environment of Recife and shows how the geotechnical map can contribute to the solution of the several problems of the city. The most serious problem today is the geological risk of landslides affecting the occuppied slopes during winter. The experiment of an integrated action envolving the technical, institutional and populational contributions resulted greatly successful.

\section{INTRODUÇÃO}

A Cidade do Recife apresenta várias situações de risco geológico, em que os processos do meio físico resultam deflagrados ou substancialmente acelerados pela presença do homem. Efeitos danosos podem-se apresentar, com perdas de vida e bens econômicos, além do prejuízo na qualidade de vida dentro do espaço urbano (GUSMÃO FILHO, 1993).

É o caso dos processos de erosão e deslizamento nos morros urbanos ocupados, onde são freqüentes os escorregamentos de várias formas e extensão. São milhares de pessoas ameaçadas no inverno, já tendo sido alto o número de vítimas fatais, atingindo mais de 50 mortes anuais.

Este trabalho mostra a contribuição da carta geotécnica na solução desses problemas e descreve a experiência desenvolvida nos morros do Recife, caracterizada pela integração da ação técnica, institucional e comunitária, de modo a reverter o quadro de risco. São apresentados os condicionantes do meio físico, social e político que tiveram rebatimento no trabalho técnico. A nova filosofia de trabalho envolve a concepção das soluções, a definição das prioridades e a execução de obras. A avaliação dos resultados conclui pelo êxito com a integração de ações e aponta as dificuldades e limitações dos agentes para garantir a sua continuidade.

\section{DADOS DO MEIO FÍSICO}

A Cidade do Recife espalha-se pela planície fluviomarinha, formada pela junção do Rios Capibaribe e Beberibe ante o Oceano Atlântico, e pelos morros que a circunscrevem, tendo ao norte a Cidade de Olinda e ao sul os Montes Guararapes, ambos sítios históricos ligados ao patrimônio artístico e cultural do Brasil. A cidade tem um subsolo reconhecidamente complexo, do ponto de vista geotécnico (GUSMÃO FILHO, 1982). A figura 1 mostra o mapa geológico da cidade.

\subsection{Os morros}

O Grupo Barreiras é a unidade geológica mais importante nos morros ocupados da Cidade do Recife. No fim do Terciário, o limite do continente e resultante do basculamento de sua borda, depositou-se o Grupo Barreiras, constituído de sedimentos de granulometria variada, caracterizados por uma mistura de areias e argilas, com horizontes de seixos suborizontais, levemente direcionados para o mar na forma de tabuleiros elevados (50m). A deposição dessa unidade geológica se deu sob a forma de leques aluviais e de depósitos fluviais de canais entrelaçados, apresentando as fácies fluviolagunar e planície aluvial (ALHEIROS et al., 1988). 
Os estudos geológicos identificam duas formações litologicamente distintas do Grupo Barreiras dos morros do Recife. O nível superior do Grupo Barreiras é representado pelos sedimentos da Formação Guararapes. Nos morros da zona norte da cidade observa-se a ocorrência do Solo Riacho Morno, que se apresenta cobrindo e/ou intercalando os sedimentos da Formação Guararapes. Os sedimentos do Solo Riacho Morno são de textura mais argilosa, diante dos sedimentos mais arenosos integrantes da Formação Guararapes. A mistura ou intercalação de ambos os sedimentos nos morros da zona norte resulta em uma susceptibili- dade à erosão menor do que nos morros da zona sul onde o solo é mais friável (MELO \& MENEZES, 1987, a e b). Tal fato se correlaciona com a ocorrência de voçorocas nos morros da zona sul, de horizontes mais arenosos, e com os deslizamentos mais freqüentes nos morros da zona norte, de sedimentos mais argilosos.

Outras unidades geológicas presentes nos morros do Recife são solos derivados do Cristalino e da Formação Cabo, limitados a pequenas manchas na zona oeste do município, onde também a ocupação é mais rarefeita. Já as Formações Beberibe e Gramame limitam-se a afloramentos sem expressão geográfica.

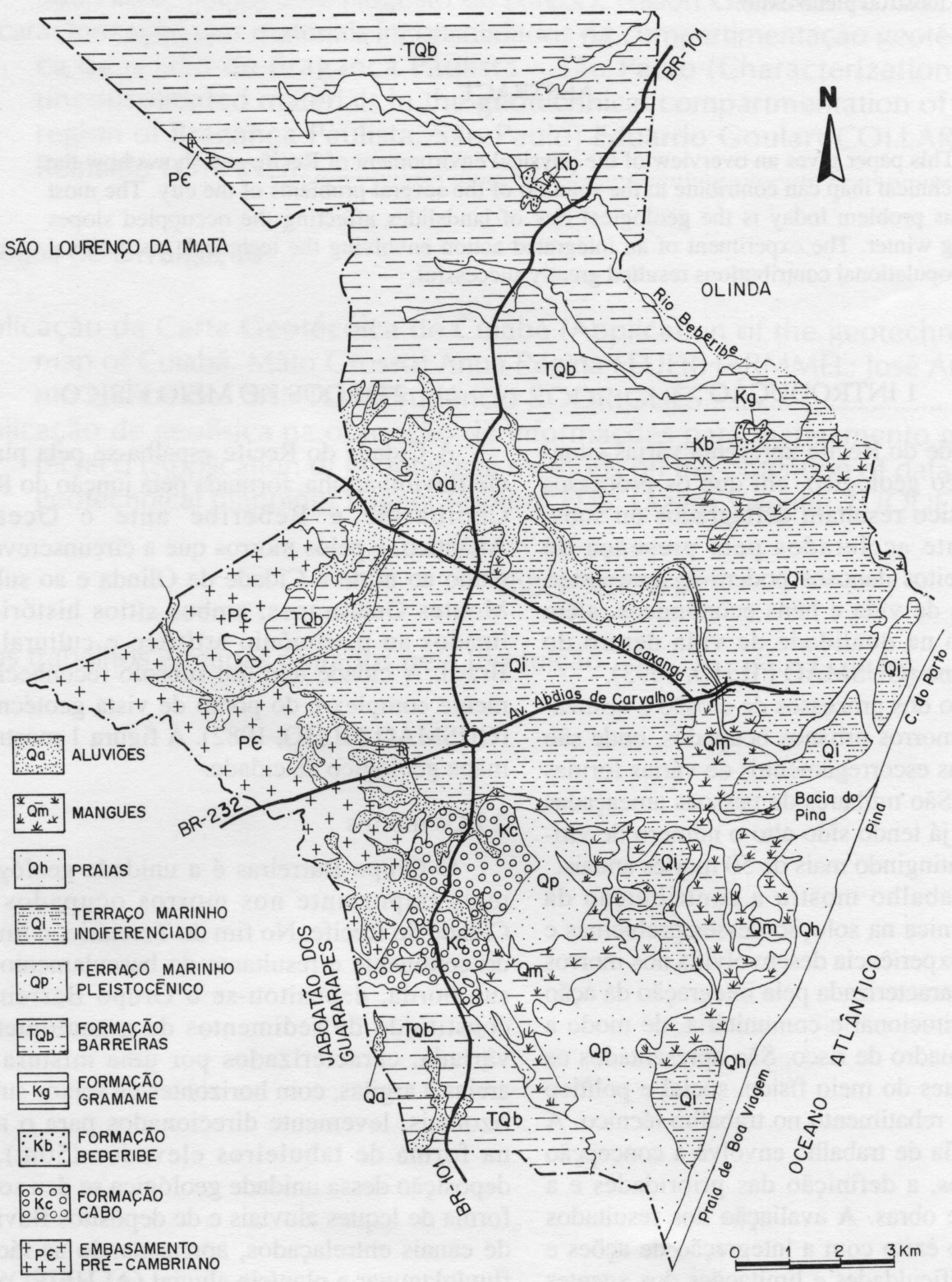

FIGURA 1 - Mapa Geológico do Recife (ALHEIROS et al., 1989). 
Quanto às encostas ocupadas, levantamento recente de campo abrangendo mais de 200 localidades do Recife mostra que têm os seguintes valores médios: altura $39 \mathrm{~m}$, declividade $29 \%$ e extensão de $314 \mathrm{~m}$. A maioria apresenta curvas de nível sinuosas $(41,5 \%)$ ou côncavas $(35,1 \%)$ e o perfil de encosta também côncavo $(45,8 \%)$. A forma de cabeceira de drenagem propicia a concentração do fluxo d'água no talvegue formando córregos. Em 60 áreas críticas do ponto de vista de risco à população, a maioria das encostas é do tipo plana na forma, subvertical em declividade e tem menos de $20 \mathrm{~m}$ de altura (GUSMÃO FILHO, 1990).

Constituídos de sedimentos não consolidados em uma região onde os índices pluviométricos são, em média, $2.000 \mathrm{~mm}$ anuais, os morros da Cidade do Recife têm na cobertura vegetal um fator de estabilização contra os processos erosivos. Da primitiva Mata Atlântica res- tam alguns vestígios em áreas de preservação rigorosa, tendo sido substituída por gramíneas, árvores frutíferas de diferentes portes ou mesmo nenhuma cobertura vegetal. A principal causa do desmatamento pode ser identificada pela ocupação do homem para assentamentos urbanos. Os morros têm, também, uso intensivo como jazidas para aterros.

\subsection{A planície}

O espaço confinado entre o morro e a orla marítima constitui-se em uma grande planície fluviomarinha, cujos sedimentos são bastante variáveis. Aí os estudos geológicos para a confecção da carta geotécnica da cidade identificaram dois níveis de terraços marinhos arenosos, correspondentes à penúltima e última transgressão marinha, além de depósitos de mangues, sedimentos fluviolagunares e aluviões (LIMA FILHO \& ALHEIROS, 1990).

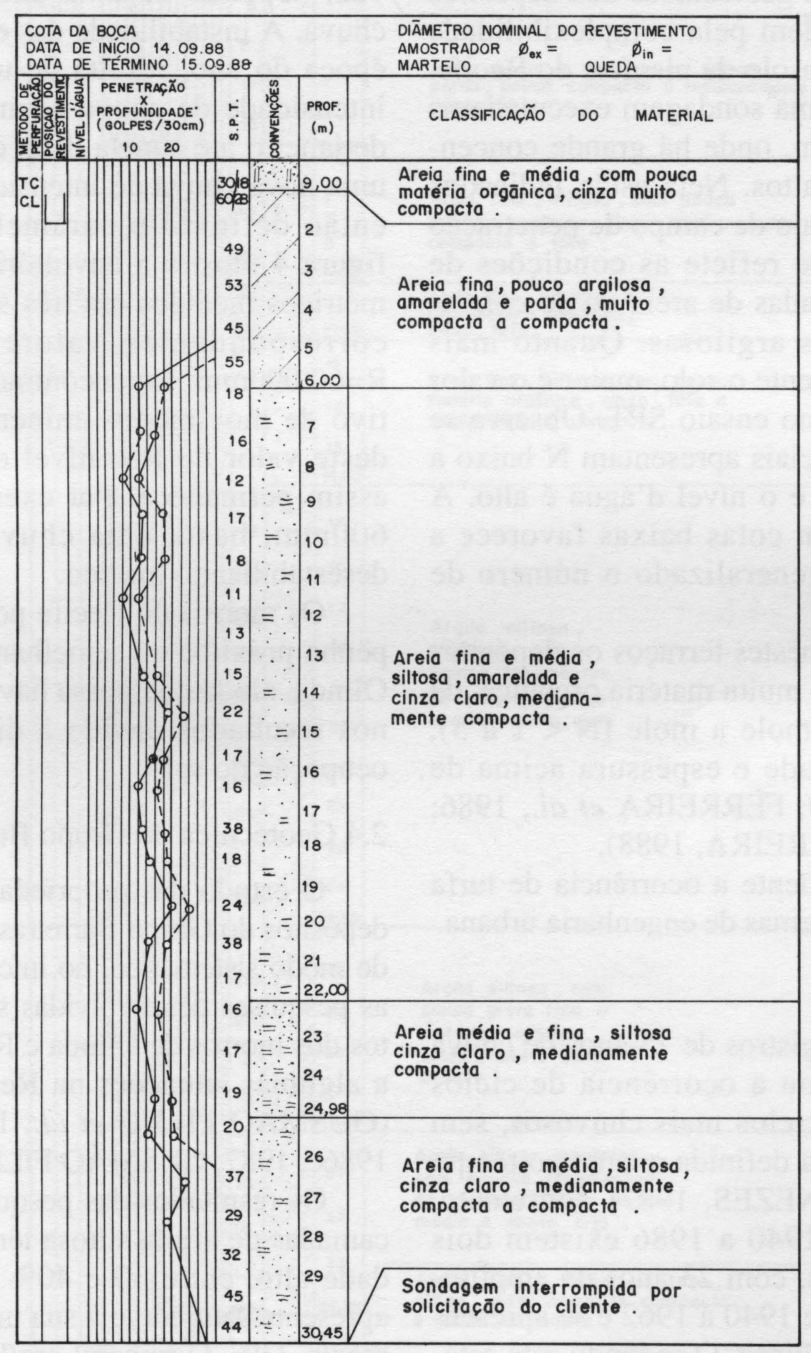

FIGURA 2 - Perfil de Sondagem no Terraço Marinho Pleistocênico, Bairro do Ibura, Recife. 
Os terraços marinhos pleistocênicos se apresentam em cotas mais elevadas ( 7 a $8 \mathrm{~m}$ ) e oferecem, em geral, excelentes condições de subsolo para fins de fundações de edifício, a exemplo da sondagem mostrada na Figura 2, no bairro do Ibura. As areias de quartzo formam um arenito compacto a partir dos 3 a $5 \mathrm{~m}$ de profundidade e os depósitos finos fluviolagunares se constituem em argila arenosa de consistência crescente, geralmente pré-adensadas no trecho inferior.

Os terraços marinhos holocênicos se apresentam em cotas mais baixas ( 2 a $5 \mathrm{~m})$ e se adentram pelo restante da planície como indiferenciado, em face das modificações trazidas pelo Rio Capibaribe, que deixou terraços fluviais, pântanos turfosos, meandros abandonados e bancos de areia, em sua trajetória para uma foz depositária dos sedimentos transportados para o mar e retidos pelos arrecifes à frente do continente.

As propriedades geotécnicas dos depósitos holocênicos respondem pela complexibilidade que caracteriza o subsolo da planície do Recife. A figura 3 mostra uma sondagem executada na praia de Boa Viagem, onde há grande concentração de edifícios altos. Nela estão indicados os resultados do ensaio de campo de penetração dinâmica (SPT) que reflete as condições de capacidade das camadas de areia ou de consistência das camadas argilosas. Quanto mais compacto ou consistente o solo, maior é o valor do índice $\mathrm{N}$ obtido no ensaio SPT. Observa-se que os solos superficiais apresentam $\mathrm{N}$ baixo a moderado $(\mathrm{N}<10)$ e o nível d'água é alto. A topografia plana em cotas baixas favorece a inundação, sendo generalizado o número de aterros nestas áreas.

São freqüentes nestes terraços os depósitos de argila siltosa com muita matéria orgânica, de consistência muito mole a mole $(\mathrm{N}<1$ a 3$)$, alta compressibilidade e espessura acima de 25m (COSTA, 1960; FERREIRA et al., 1986; COUTINHO \& FERREIRA, 1988).

Também é freqüente a ocorrência de turfa trazendo sérios problemas de engenharia urbana.

\subsection{Pluviometria}

O estudo dos registros de 75 anos de chuva (1912-1986) mostrou a ocorrência de ciclos menos chuvosos e ciclos mais chuvosos, sem existir uma tendência definida quanto ao tempo de alternância (MENEZES, 1987). Entretanto, para o período de 1940 a 1986 existem dois ciclos bem definidos, com 23 anos de amplitude. O primeiro vai de 1940 a 1962 e se apresenta como o menos chuvoso. O segundo está estabelecido de 1963 a 1986. As precipitações totais anuais médias para estes dois ciclos são de $1.008 \mathrm{~mm}$ e $2.483 \mathrm{~mm}$, respectivamente. O último ciclo identificado, 1963-1986, é um período mais chuvoso, onde $87,5 \%$ das precipitações totais anuais são superiores à média do ciclo, tendo havido a ocorrência de inúmeros desabamentos com vítimas fatais.

O monitoramento das chuvas constitui uma estratégia extremamente importante na prevenção de acidentes em áreas de risco, como as dos morros da Cidade do Recife. Neste sentido uma significativa contribuição foi trazida pelas pesquisas realizadas visando identificar o mecanismo de movimento de morros de Olinda, que também são do Grupo Barreiras, e ficam na divisa junto aos morros da zona norte do Recife (GUSMÃO FILHO et al., 1987). Há uma importante interação entre a precipitação local e o desempenho do maciço. Foi constatado que a estabilidade das encostas é reduzida com a elevação do nível piezométrico que, por sua vez, depende de uma dada configuração de chuva. A instabilidade das encostas, numa certa época do ano, resulta de uma combinação da intensidade de chuva acumulada Pac, a partir de janeiro até àquela data, com a ocorrência de uma nova chuva de intensidade mínima I1. Foi então definido o parâmetro $\mathrm{R}=\mathrm{Pac} \times \mathrm{I} 1$. A figura 4 mostra a envoltória dos níveis piezométricos medidos em três sítios históricos e os correspondentes valores de R. O valor $\mathrm{R}=60.000 \mathrm{~mm}^{2}$ foi encontrado como representativo de movimento iminente, porque a partir deste valor de $\mathrm{R}$ o nível d'água é máximo e assim permanece. Por exemplo, se já choveu $600 \mathrm{~mm}$, basta uma chuva de $100 \mathrm{~mm}$ para desestabilizar o maciço.

Os morros do Recife podem ter um desempenho próximo ou semelhante ao observado em Olinda, ainda que possa haver alguma diferença nos resultados devido à diferença no tipo de ocupação do solo.

\subsection{Geotécnica do Grupo Barreiras}

O estudo das propriedades geotécnicas dos depósitos do Grupo Barreiras começou a ser feito, de modo sistemático, no início dos anos 80 , com as pesquisas desenvolvidas sobre os deslizamentos dos morros de Olinda e Recife, estendendo-se a algumas situações na Região Metropolitana (GUSMÃO FILHO et al., 1982; 1986a; 1986b; 1986c; 1987; GUSMÃO FILHO, 1990).

Os resultados das pesquisas revelam que as camadas de argila siltosa têm índice de plasticidade alto, entre 30 e $40 \%$. O material não se apresenta saturado e a sua umidade natural é em média $23 \%$. O mineral argílico preponderante é caulinita, situando-se na faixa das argilas inati- 
vas e normais. É pré-adensada, com pressões de pré-adensamento entre 150 e $260 \mathrm{kPa}$. O préadensamento pode ser atribuído a várias causas, como ressecamento, erosão supercial e/ou variação do nível d'água. A hipótese de ressecamento é justificada pela existência de grau de saturação inferior a $100 \%$.

Os parâmetros de compressibilidade obtidos para os depósitos argilosos do Grupo Barreiras, nos morros de Olinda vizinhos ao Recife, mostram valores baixos para o índice de compressão, variando entre 0,15 e 0,30 , enquanto o índice de recompressão fica em torno de $10 \%$ destes valores. No trecho de compressão virgem, o coeficiente de adensamento vertical varia de $10^{-8}$ a $10^{-7} \mathrm{~m}^{2 / \mathrm{s}}$ (GUSMÃO FILHO et al., 1986a).

Os resultados da pesquisa também mostram que a influência da compressão secundária (índice de 0,13 a 0,32 ) na deformação total é pequena comparada com a deformação de compressão primária. A influência da água na saturação do maciço é, assim, mais significativa do que a influência da compressão secundária. Daí a importância das chuvas e da infiltração efetiva, que são fatores mais importantes do que o

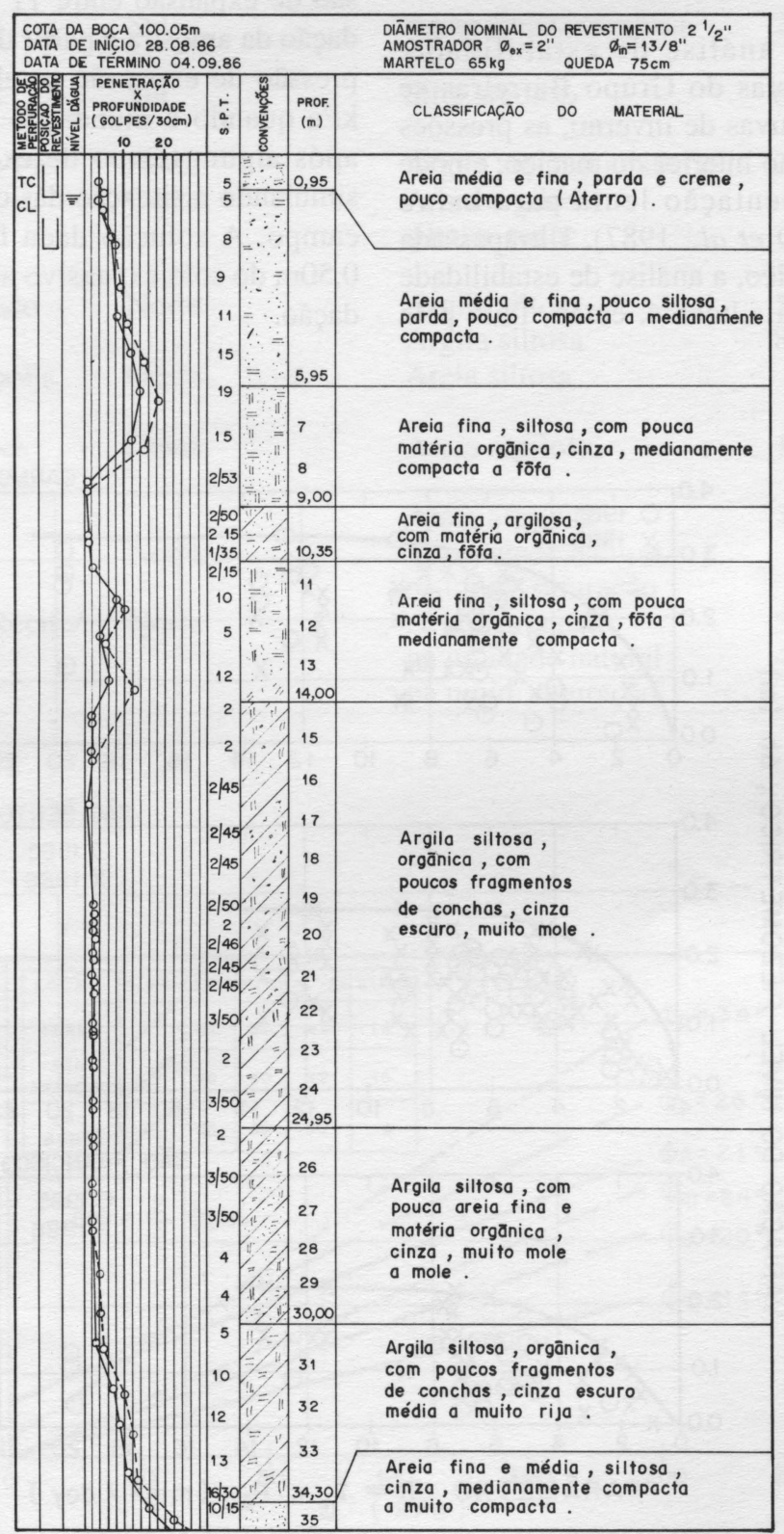

FIGURA 3 - Perfil de Sondagem no Terraço Marinho Holocênico, na Av. Boa Viagem, Recife. 
tempo, nos recalques observados nos monumentos de Olinda.

Quanto à resistência dos solos do Grupo Barreiras, o quadro I apresenta resultados de ensaios de resistência ao cisalhamento direto em vários locais da Região Metropolitana do Recife.

Nos morros de Olinda foram realizados ensaios de cisalhamento direto com reversão múltipla, para vários ciclos consecutivos de ruptura na mesma amostra cisalhada, com inundação inicial. O ensaio realizado difere do convencional para obtenção do ângulo de atrito residual $\emptyset_{\mathrm{r}}$. O resultado pode, então, ser chamado de ângulo de atrito quase residual $\phi$ qr e seu valor obtido é $2 / 3$ do ângulo de atrito de pico (Fig. 5).

Para fins de análise de estabilidade, enquanto as encostas do Grupo Barreiras se saturam com as chuvas de inverno, as pressões neutras se elevam no interior do maciço, e pode se iniciar movimentação lenta para baixo (GUSMÃO FILHO et al., 1987). Ultrapassada a resistência $\emptyset$ de pico, a análise de estabilidade no trecho de argila siltosa é, então, feita pela resistência residual, na qual deve ser adotado um valor 2/3 dos indicados no Quadro I, para o ângulo de atrito.

Em certas camadas do Grupo Barreiras foram encontradas propriedades expansivas, a exemplo do morro Burity (Fig. 6). Na implantação de um conjunto da $\mathrm{COHAB}$, vários cortes foram dados para execução das plataformas de assentamento das casas. Na plataforma de cota $57 \mathrm{~m}$, onde o corte correspondeu a mais de $10 \mathrm{~m}$, foi constatada a presença de argila expansiva, provocando danos nas casas de alvenaria ainda em construção, após as primeiras chuvas. Ensaios de laboratório confirmaram uma pressão de expansão entre 11 e $23 \mathrm{kPa}$, com inundação da amostra a partir da umidade natural. A pressão de expansão se elevou a mais de 100 $\mathrm{kPa}$ quando a inundação da amostra foi feita após algum tempo de exposição ao ar livre, simulando a situação das cavas de fundação no campo. A solução dada foi a substituição de $0,50 \mathrm{~m}$ do solo expansivo abaixo da cota de fundação.

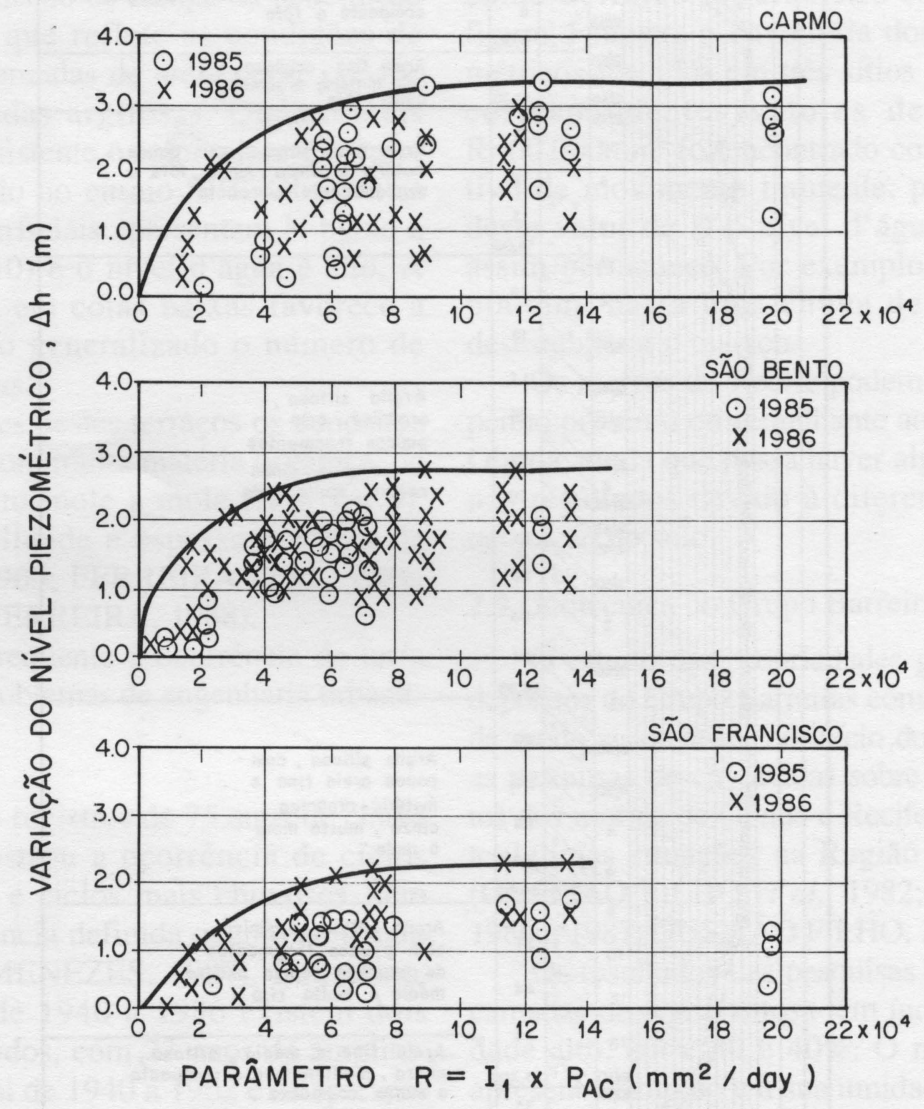

FIGURA 4 - Relação entre Nível Piezométrico e Precipitação, Olinda (GUSMÃO FILHO et al., 1987). 
QUADRO I - Parâmetros de Resistência do Grupo Barreiras

\begin{tabular}{|c|c|c|c|c|}
\hline LOCAL & ZONA & $\begin{array}{l}\text { DESCRIÇÃO } \\
\text { DO SOLO }\end{array}$ & $\begin{array}{l}\text { COESÃO } \\
(\mathrm{kPa})\end{array}$ & $\begin{array}{l}\text { ÂNGULO } \\
\text { ATRITO }\end{array}$ \\
\hline $\begin{array}{l}\text { Encosta Olho D'água } \\
\text { Casa Amarela/Recife }\end{array}$ & Norte & Argila siltosa & 32 & 24 \\
\hline Alto do Reservatório & Norte & Areia argilosa & 7 & 31 \\
\hline Corr. Joaquim/Recife & & Areia argilosa & 11 & 28 \\
\hline $\begin{array}{l}\text { Alto N.S. de Fátima } \\
\text { Boqueirão/Recife }\end{array}$ & Norte & $\begin{array}{l}\text { Areia argilosa } \\
\text { amarela }\end{array}$ & 25 & 17 \\
\hline $\begin{array}{l}\text { Morro do Carmo } \\
\text { Olinda/PE }\end{array}$ & Norte & Argila siltosa e arenosa & 53 & 18 \\
\hline $\begin{array}{l}\text { Morro do Carmo } \\
\text { Olinda/PE }\end{array}$ & Norte & Argila siltosa e arenosa & 46 & 23 \\
\hline $\begin{array}{l}\text { Monte Guararapes } \\
\text { Jaboatão/PE }\end{array}$ & Sul & Areia siltosa & 10 & 35 \\
\hline $\begin{array}{l}\text { Monte Guararapes } \\
\text { Jaboatão/PE }\end{array}$ & Sul & Areia siltosa argilosa & 22 & 31 \\
\hline $\begin{array}{l}\text { Monte Guararapes } \\
\text { Jaboatão/PE }\end{array}$ & Sul & Silte arenoso & 64 & 35 \\
\hline Morro em Paulista PE & Norte & Argila arenosa amarela & 22 & 38 \\
\hline $\begin{array}{l}\text { Morro em Curado } \\
\text { Recife/PE }\end{array}$ & Oeste & $\begin{array}{l}\text { Areia argilosa } \\
\text { siltosa roxa }\end{array}$ & - & 28 \\
\hline Morro São Francisco & Norte & Argila siltosa & 50 & 21 \\
\hline Olinda/PE & & Argila siltosa & 85 & 22 \\
\hline $\begin{array}{l}\text { Lot. Jardim Petrópolis } \\
\text { Camaragibe/PE }\end{array}$ & Oeste & Areia siltosa & - & 30 \\
\hline $\begin{array}{l}\text { Rua Belmiro Correa } \\
\text { Camaragibe/PE }\end{array}$ & Oeste & Areia argilosa & 15 & 26 \\
\hline $\begin{array}{l}\text { Morro do Burity } \\
\text { Recife/PE }\end{array}$ & Norte & $\begin{array}{l}\text { Areia argilosa } \\
\text { na umidade natural } \\
\text { na umid. saturação }\end{array}$ & 39 & 26 \\
\hline $\begin{array}{l}\text { Morro do Burity Recife/ } \\
\text { PE }\end{array}$ & Norte & $\begin{array}{l}\text { Argila arenosa } \\
\text { na umidade natural } \\
\text { na umid. saturação }\end{array}$ & $\begin{array}{l}52 \\
43\end{array}$ & 25 \\
\hline
\end{tabular}

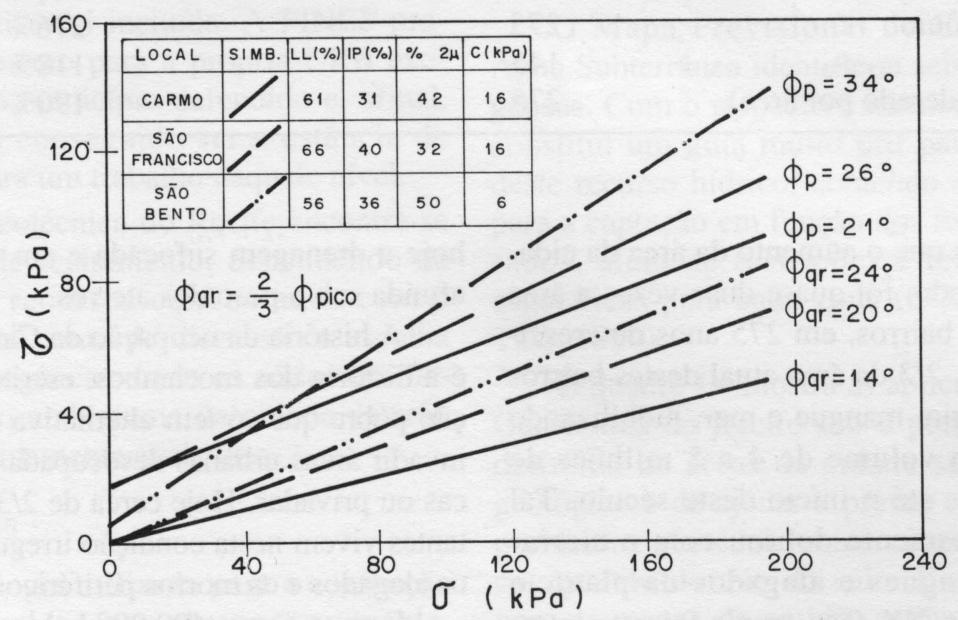

FIGURA 5 - Resistência ao Cisalhamento das Argilas, Grupo Barreiras (GUSMÃO FILHO et al., 1986a). 


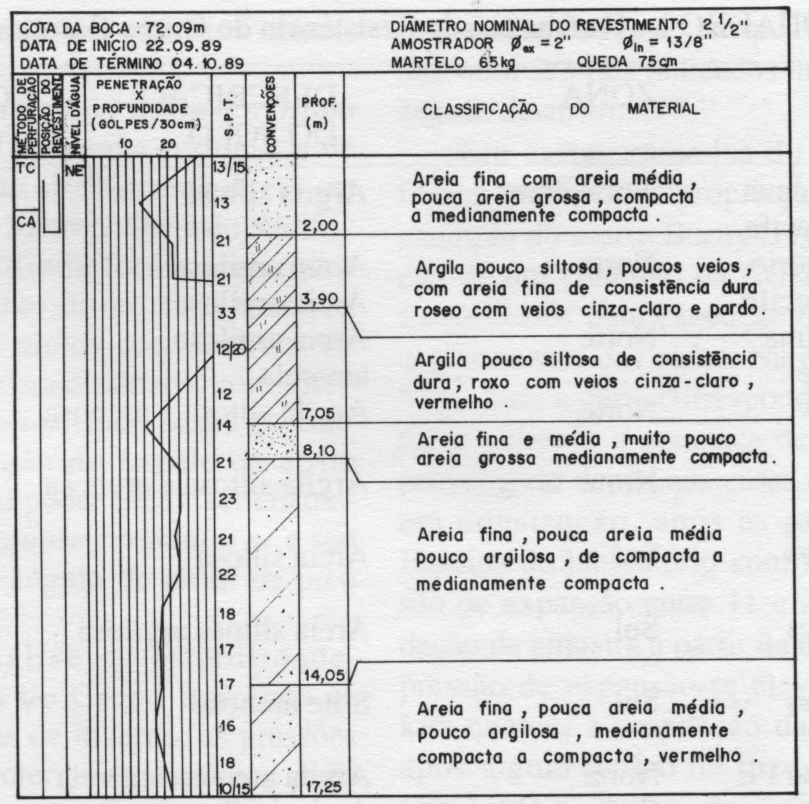

FIGURA 6 - Perfil de Sondagem no Grupo Barreiras, Morro do Burity, Recife.

\section{A EXPANSÃO URBANA}

A Cidade do Recife tem $220 \mathrm{~km}^{2}$ e cresceu do mar para o interior, em círculos crescentes, tomando o espaço das águas dos mangues e dos alagados por sucessivos aterros. Sua população hoje é cerca de 1,40 milhão de habitantes.
Pesquisa recente, ainda inédita e realizada pelo Autor, com base nos mapas de cartografia histórica (MENEZES, 1988) e perfis de sondagens geotécnicas, mostra o aumento de área nos bairros mais antigos da cidade, até o início deste século, conforme se verifica no quadro II.

QUADRO II - Crescimento da Cidade do Recife

\section{BAIRROS}

Recife

Santo Antônio

Boa Vista

Total (ponderado por área)
TEMPO (anos)
PERCENTUAL DE AUMENTO DA ÁREA PRIMITIVA
Observa-se que o aumento da área da cidade, como um todo, foi quase duas vezes a área inicial dos três bairros, em 275 anos de crescimento. Ou seja, 2/3 da área atual destes bairros foi tomada do rio, mangue e mar, mobilizando para aterro um volume de 4 a 5 milhões de metros cúbicos, até o início deste século. Tal volume simplesmente dobrou com o aterramento dos mangues e alagados da planície durante o século XX. Tão ampla foi esta intervenção no seu meio físico, que a cidade tem hoje a drenagem sufocada e em muitos pontos afunda sob o peso dos aterros.

A história da ocupação da Cidade do Recife é a história dos mocambos, escrita pela população pobre que só tem alternativa de moradia se invadir áreas urbanas desocupadas, sejam públicas ou privadas. Hoje cerca de $2 / 3$ de seus habitantes vivem nesta condição irregular, ocupando os alagados e os morros periféricos.

Estima-se em 400.000 habitantes a população dos morros do Recife. Aí também se con- 
centra um grande índice de pobreza urbana. O fluxo migratório, acentuado em consequiência do êxodo rural, formou um cinturão na periferia da cidade que concentra, também, a periferia econômica e social da população.

\section{A CARTA GEOTÉCNICA DO RECIFE}

Em sua evolução, o Recife acumulou erros que o planejamento não foi capaz de evitar. A cidade cresceu ignorando os condicionamentos do meio físico. Algumas das conseqüências daí decorrentes estão entre os atuais problemas da cidade. Estes problemas se caracterizam como situação de risco geológico podendo apresentar sérios prejuízos financeiros, ambientais e até perdas de vida. Trabalho recente (GUSMÃO FILHO, 1993) apresenta um levantamento detalhado dos riscos da cidade: deslizamentos, subsidência de aterro, uso de água subterrânea, inundação, erosão marinha e sedimentação. A Carta Geotécnica do Recife pode ser um dos instrumentos de ajuda para reduzir estes riscos e disciplinar o uso do solo urbano.

\subsection{Histórico}

Com os trágicos deslizamentos dos morros no início dos anos 80, o Laboratório de Solos e Instrumentação, do Departamento de Engenharia Civil da UFPE, apresentou projeto à FINEP visando à confecção da carta geotécnica. Foi exigida contrapartida financeira do órgão municipal, que se interessou pelo projeto sem contudo dar-lhe apoio. Somente em 1987 o convênio foi firmado, por interferência exitosa da mesma Prefeitura Municipal. Ao negociar vários projetos de pesquisa com a FINEP, a Empresa de Urbanização do Recife (URB/RECIFE) apresentou o plano de trabalho nos morros em convênio com a UFPE, no qual a carta geotécnica foi incluída. A FINEP propôs o financiamento para a própria URB executá-la, tendo o município defendido e, afinal, a universidade conseguido ser a estância de competência para um trabalho daquele nível.

A Carta Geotécnica do Recife encontra-se hoje em fase de fechamento, dependendo da liberação dos recursos conveniados com a FINEP. Está em ponto de discussão a escolha das zonas homogêneas, onde os sérios problemas geotécnico-ambientais da cidade estarão incluídos e devidamente avaliados.

\subsection{Metodologia}

A metodologia utilizada para a confecção da carta geotécnica visou abranger os problemas reais e potenciais oriundos da interação entre a urbanização e o meio físico, procurando o entendimento dos condicionantes e os mecanismos dos fenômenos envolvidos e a sua distribuição espacial de ocorrência ou de potencial manifestação (COUTINHO et al., 1990). Os trabalhos foram divididos em 4 subáreas básicas: Cartografia, Geologia/Geologia de Engenharia, Água Subterrânea e Geotecnia, com o objetivo de obter os seguintes produtos:

mapas analíticos ou básicos, pertinentes a informações e levantamentos específicos de cada uma destas subáreas;

mapas de aptidão ou interpretativos, onde a informação dos mapas básicos é sintetizada para um determinado fim ou utilização prática;

banco de dados de informação geotécnica, obtida junto a empresas executoras, ou usuárias de prospecção geotécnica;

carta geotécnica da cidade, onde é feita a síntese das informações relevantes em zonas homogêneas para fins de uso do solo.

O quadro III mostra os estudos temáticos procedidos por subáreas.

\subsection{Resultados}

O Mapa Geológico, direcionado para fins de engenharia e já concluído, contém dez unidades geológicas. $\mathrm{O}$ memorial descritivo que o acompanha traz informação relevante para fins de projetos de urbanização e execução de obras, como as características texturais e profundidade dos depósitos, o perfil dos solos desenvolvidos, posição do NA, forma do relevo. A resistência relativa dos materiais encontrados pode ser inferida com descrições, a exemplo de presença de argila orgânica mole, areia concrecionada, conchas etc. (ALHEIROS, et al., 1989).

O Mapa Previsional de Explotação de Água Subterrânea identificou seis zonas homogêneas. Com o respectivo memorial descritivo, constitui um guia muito útil para os usuários deste recurso hídrico, contendo dados práticos para a captação em função dos resultados esperados, além de restrições e recomendações específicas para cada zona (COSTA \& SANTOS, 1990).

O quadro IV mostra as aplicações da Carta Geotécnica do Recife sob o ponto de vista de delimitar as áreas da cidade sujeitas a risco geológico e de ajudar a prever e solucionar os problemas geotécnicos inerentes ao meio físico, quando do uso do solo. É dado destaque para os mapas de aptidão cujos subsídios são usados nas aplicações da carta geotécnica. 
QUADRO IV - Aplicações da Carta Geotécnica do Recife

\begin{tabular}{|c|c|c|}
\hline \multirow[t]{2}{*}{ MAPA DE APTIDÃO } & \multicolumn{2}{|c|}{ APLICAÇÕES } \\
\hline & RISCO GEOLÓGICO & PROBLEMA GEOTÉCNICO \\
\hline - Elementos morfológicos & $\begin{array}{l}\text { - Deslizamentos } \\
\text { - Erosão } \\
\text { - Sedimentação }\end{array}$ & $\begin{array}{l}\text { - Tratamento dos morros } \\
\text { - Jazidas urbanas } \\
\text { - Assoreamento na planície } \\
\text { - Dragagem }\end{array}$ \\
\hline $\begin{array}{l}\text { - Áreas de depósitos } \\
\text { de argila mole }\end{array}$ & $\begin{array}{l}\text { - Subsidência por aterros } \\
\text { - Subsidência por uso de } \\
\text { água subterrânea } \\
\text { - Inundação }\end{array}$ & $\begin{array}{l}\text { - Drenagem da área } \\
\text { - Infra-estrutura/saneamento } \\
\text { - Greide das edificações } \\
\text { - Fundações } \\
\text { - Escavações } \\
\text { - Aterros }\end{array}$ \\
\hline $\begin{array}{l}\text { - Explotação de água } \\
\text { subterrânea }\end{array}$ & $\begin{array}{l}\text { - Exaustão } \\
\text { - Contaminação } \\
\text { - Subsidência }\end{array}$ & $\begin{array}{l}\text { - Abastecimento } \\
\text { - Aterros sanitários } \\
\text { - Problemas de subsidência }\end{array}$ \\
\hline
\end{tabular}

O Plano Diretor do Recife prevê um elenco de projetos, planos, códigos e controles para fins de urbanização, preservação ambiental e implantação de obras de infra-estrutura, muitos deles ainda não iniciados. A carta geotécnica poderá, então, dar relevante contribuição ao planejamento da Cidade do Recife.

\section{MODELO DE OCUPAÇÃO DAS ENCOSTAS}

As encostas ocupadas do Recife abrangem uma área de $33 \mathrm{~km}^{2}$, correspondente à metade da área dos morros e $15 \%$ da área do municí- pio. A ocupação dos terrenos de encosta, de um modo geral, se dá de forma ilegal, desordenada e concentradora de problemas, uma vez que se transformam em áreas de risco geológico urbano. O quadro $\mathrm{V}$ sintetiza o modelo de ocupação nos morros da zona norte, oeste e sul do Recife.

São as seguintes as características principais do modelo de ocupação observadas nos morros habitados do Recife:

- remoção de vegetação natural;

QUADRO V - Ocupação dos Morros do Recife

\begin{tabular}{|c|c|c|c|}
\hline PARÂMETROS & ZONA NORTE & ZONA OESTE & ZONA SUL \\
\hline - Modelo de ocupação & $\begin{array}{l}\text { - Desordenada por } \\
\text { população de baixa } \\
\text { renda, com predomi- } \\
\text { nância de invasões }\end{array}$ & $\begin{array}{l}\text { - Conjuntos habitacionais, } \\
\text { ocupação informal } \\
\text { consolidada e algumas } \\
\text { invasões }\end{array}$ & $\begin{array}{l}\text { - Conjuntos habita- } \\
\text { cionais da COHAB } \\
\text { nos topos planos e } \\
\text { invasões nas encostas }\end{array}$ \\
\hline - Área ocupada & 1850 ha & 425 ha & $1.025 \mathrm{ha}$ \\
\hline • População & 280.000 hab & 8.000 hab & 92. $000 \mathrm{hab}$ \\
\hline - Densidade média & 150 hab/ha & $20 \mathrm{hab} / \mathrm{ha}$ & $90 \mathrm{hab} / \mathrm{ha}$ \\
\hline
\end{tabular}

- corte horizontal para o assentamento da casa;

- corte íngreme atrás, para um terreno maior;

- casa localizada no bordo do talude;

- plantação de árvores no bordo do talude;

- ausência de calhas, biqueiras e calçadas;

- ausência de drenagem pluvial;

- fossa localizada no bordo do talude;

- lixo jogado sobre o talude;
- drenagem natural obstaculada por lixo.

Com o tempo, novos cortes são feitos para aumentar a área de ocupação da casa, devido aos novos filhos, ao casamento ou à chegada de outros familiares vindos do meio rural. É um quadro que propicia a desestabilização das encostas no inverno, ameaçando a segurança de seus moradores.

Este modelo de ocupação desordenada é, de longe, a maior causa de desequilíbrio das 
encostas. No modelo conservacionista prevalecem os fatores fisiográficos e geológicos sobre os antrópicos. Mas no modelo de ocupação caótico prevalecem os efeitos ambientais da ação do homem sobre os outros fatores (GUSMÃO FILHO et al., 1984).

Análise de risco coordenada pelo Autor, em mais de 200 encostas ocupadas do Recife, ainda inédita, confirma esta conclusão. Os resultados mostram que a maior contribuição para o risco final à erosão e deslizamento destas encostas é dada pelos fatores ambientais em $55,4 \%$ dos casos, pelos fatores topográficos em $44,1 \%$ e pelos fatores geológicos em somente $0,5 \%$ do total. Nas encostas onde o grau de risco é alto a muito alto, a contribuição dos fatores ambientais para esta situação de risco sobe $75,4 \%$. O uso do solo pelo homem é, assim, a principal causa que induz eventos desastrosos.

\section{PROGRAMA DE AÇÃO INTEGRADA}

Os órgãos municipais vinham convivendo com esta situação de risco geológico permanente nos morros e atuando mais sobre o impacto das pressões e dos fatos consumados do que do planejamento através de ações programadas, a exemplo de:

- intervenções tópicas, isoladas, sem se interligarem na lógica de um tratamento ambiental da área em questão;

- ênfase na construção de muros de arrimo de pedra atrás das habitações, sem que fossem parte de uma intervenção global;

- atendimento a pleitos individuais dos moradores, encaminhados por políticos;

- trabalho concentrado na estação das chuvas em decorrência dos seus efeitos calamitosos.

No triênio 1986/1988 a nova administração municipal deu prioridade à questão dos morros, resultando numa programação de ações e responsabilidades técnicas, institucionais e da população envolvida. As ações derivam do entendimento de como se comportam o meio físico e o corpo social ocupante da área (GUSMÃO FILHO, 1987).

Ao invés de soluções individuais com intervenção tópica e emergencial, partiu-se para conhecer a unidade receptora, cujas características morfológicas, litológicas e hidráulicas devem ser devidamente avaliadas na definição de soluções globais para reduzir o risco geológico dos deslizamentos.

A partir desta conceituação, a metodologia de trabalho envolve estudos e pesquisas das características gerais da área e de cada encosta, da cobertura vegetal, dos dados hidrológicos, geológicos e geotécnicos, permitindo, ao termo, o mapeamento das áreas com potencialidade de risco geológico em diferentes graus. A partir daí, dispõe-se de um poderoso instrumento para estabelecer prioridades, definir as intervenções mais efetivas e instalar sistema de controle nos pontos críticos.

Esta programação foi conduzida por uma equipe técnica de alto nível, de engenheiros e geólogos do município trabalhando com professores e pesquisadores da universidade. A sua missão era não só gerar a informação técnica mas dar, também, formação adequada ao pessoal técnico de campo envolvido diretamente com as comunidades.

Outra ação programada foi discutir com a população o que significa morar no morro. Era necessário que cada morador e cidadão tivesse consciência do que representa a moradia nos morros e da sua responsabilidade na própria segurança e na segurança dos outros moradores. Foi neste contexto que se desenvolveu a concepção de tratar o morro como um condomínio, pois a solução não deve ser individual, mas coletiva. Assim, além da estratégia de ação técnica, partiu-se para tratar o problema diretamente com a população, mobilizada através de suas lideranças.

Esta ação integrada de técnicos e população tem a sua jutificativa no fato de que o controle para assegurar estabilidade em áreas de risco deve ser efetuado através de medidas de caráter corretivo, seguido de outras de caráter preventivo, necessitando de um permanente acompanhamento e conservação das soluções adotadas.

\section{O PROCESSO E OS RESULTADOS}

A nova concepção instalou um processo de intervenção nas áreas de morro do Recife com o qual as populações e técnicos passaram a conviver.

Inicialmente foi realizado um levantamento geológico-geotécnico de todas as áreas de instabilidade, resultando num conjunto de informação especializada obtida através de visitas, estudos e pesquisas feitas nos morros. A própria população informava diretamente aos técnicos as áreas consideradas críticas pelo povo. Com base em todos estes dados e no registro de acidentes ocorridos nos últimos anos, as áreas foram, tentativamente, agrupadas em quatro categorias de risco e degradação ambiental (MELO et al., 1987 c).

A partir destes grupamentos eram então estabelecidas as áreas prioritárias e as soluções a adotar. Considerando a importância da participação da população na solução dos pro- 
blemas, a seleção das áreas era, também, compatibilizada com o grau de organização e reivindicação do movimento popular representativo em cada área.

Definida a área, partia-se para elaborar o projeto básico, estabelecendo as intervenções. A partir do projeto básico iniciava-se o ciclo de negociação com as comunidades, através de uma série de reuniões com as entidades e grupos sociais organizados e a presença dos dirigentes, engenheiros e técnicos da área social, com o objetivo de:

- expor a filosofia do programa e projetos básicos de infra-estrutura física;

- propor a participação e o envolvimento dos moradores das áreas de intervenção;

- propor a formação de comissões para acompanhar e fiscalizar as obras;

- criar foruns semanais, onde são discutidos e encaminhados os problemas das obras.
Para ampliar a participação e o conhecimento da população realizavam-se palestras sistemáticas com a apresentação de slides pelos técnicos, para levar a população à tomada de consciência de suas responsabilidades e apresentar as responsabilidades do poder público.

Aliado a isso, uma cartilha sobre os deslizamentos dos morros em linguagem popular chamava a atenção para a necessidade da consciência coletiva dos moradores, difundia ensinamentos e cobrava a conservação das obras já concluídas.

Este processo, pela primeira vez executado na administração do Recife, permitiu total transparência junto à população do conteúdo do projeto. A população já conhecia, quando do início das intervenções, o que seria e o que não seria executado, permitindo sua fiscalização real. O processo, inclusive, também explicitava os grupos de moradores que não seriam atendi-

QUADRO VI - Experiência de ação integrada nos morros do Recife

\begin{tabular}{lll}
\hline AGENTES & PERFIL EXIGIDO & DIFICULDADES \\
\hline - Gestor municipal & - Reconhecer as camadas & - Visão elitista do mundo embasada \\
& como interlocutor privilegiado & em compromissos políticos com o \\
& na definição do seu espaço. & conservadorismo. \\
& • Compromisso com a & • Uso do sigilo para barganhar \\
& transparência. & vantagens. \\
& - Aceitar a prática da & Compromissos eleitorais; demora \\
& negociação sobre a prática & nas negociações em face da rapidez \\
& clientelista. & das decisões isoladas.
\end{tabular}

- Instituição • Democratizar internamente a instituição, como rebatimento da ação externa.

- Assunção do servidor público à condição de "servo do povo" - Criar canais de comunicação informal com a população.
- Esferas de poder na instituição que não dividem as decisões.

- Baixos salários como defesa do imobilismo e corporativismo. - Burocracia como forma de evitar mudanças no poder.
Técnicos

- Qualificação para dar soluções técnica e socialmente apropriadas.

- Trabalhar com equipe multidisciplinar.

- Discutir o trabalho técnico com as comunidades envolvidas, aceitando-as como interlocutoras na solução, no cronograma, na fiscalização e na avaliação de qualidade das obras.

Comunidade • Organização em entidades representativas.

- Contrapartida de responsabilidades que a negociação exige.

- Visão política do processo de participação como resgate da cidadania.
- Formação técnica dirigida para dar soluções caras e complicadas.

- Falta de cultura geral

- Doutrina de autovalorização dos técnicos como os donos da verdade - Cultura da pequena burguesia de desprezo pelo conhecimento popular.
- Luta política, quebrando a unidade dos pleitos.

- Falta de prática política como cidadãos.

- Nível de carência da população, que luta por ações imediatas. 
dos em suas reivindicações, seja por não haver razões técnicas, ou por haver outras prioridades mais urgentes.

O processo de participação popular e de negociação coletiva, quando instalado concretamente, educa e conscientiza a população dos caminhos reais para resolver seus problemas, qualifica a intervenção da prefeitura e aumenta a capacidade da cidade de resolver seus problemas. No caso do Recife, ela permitiu, também, outros ganhos:

- implantar uma concepção nova e adequada na solução de problemas técnicos até então resolvidos pelo clientelismo;

- desmistificar o muro de arrimo junto à população pobre, como única solução para os problemas dos morros;

- ampliar a capacidade e a diversidade técnica das equipes do poder público no trato multidisciplinar;

- assegurar segurança à população, não tendo ocorrido perda de vida por deslizamento naquele período.

Por outro lado, são inúmeras as dificuldades em um processo como este, de ação inte- grada. O quadro VI mostra o perfil esperado dos agentes e as dificuldades para obtê-lo.

\section{CONCLUSÕES}

É apresentado um quadro da realidade física e ambiental da Cidade do Recife, bem como a contribuição que a carta geotécnica, atualmente em condições de fechamento, pode vir a dar para a solução dos inúmeros problemas urbanos.

Entre estes, estão as encostas ocupadas, sob o risco de deslizamento no inverno. A experiência de uma ação integrada do ponto de vista técnico, institucional e comunitário, revelou-se de pleno êxito. O trabalho faz a descrição do processo, as dificuldades encontradas e os resultados obtidos.

A experiência nos morros do Recife foi possível em face de um contexto político excepcionalmente favorável. A isso se somou a decisão de um grupo técnico, de vários saberes, de contribuir com o seu trabalho para uma efetiva melhoria na segurança e qualidade de vida de milhares de concidadãos.

\section{REFERÊNCIAS BIBLIOGRÁFICAS}

ALHEIROS, M.M.; LIMA FILHO, M.F.; MONTEIRO, F.J.; OLIVEIRA FILHO, J.S. 1988. Sistemas deposicionais da Formação Barreiras no Nordeste Oriental. In: CONGRESSO BRASILEIRO DE GEOLOGIA, 35을 Belém. Anais.v. 2, p. 759-780.

ALHEIROS, M.M.; MENEZES, M.F.; FERREIRA, M.G. 1989. Texto explicativo do mapa geológico. Carta Geotécnica do Recife. FINEP/UPPE.

COSTA, A.J. 1960. O subsolo do Recife. Publicação 19 do ITEP, Recife.

COSTA, W.D. \& SANTOS, A.C. 1990. Zoneamento para utilização de água subterrânea no município de Recife. In: CIVIL 90, Recife, ITEP. Anais.v.2, p. 521-530.

COUTINHO, R.Q. e FERREIRA, S.R.M. 1988. Argilas orgânicas do Recife Estudos de caracterização e compressibilidade em seis depósitos. In: SIMPÓSIO SOBRE DEPÓSITOS QUATERNÁRIOS DA BAIXADA LITORÂNEA BRASILEIRA, ABMS/ABGE, Rio de Janeiro. Anais. p. 2.1- 2.19.

COUTINHO. R.Q.; JUSTINO DA SILVA, J.M.; GENEVOIS, B; TEIXEIRA, D.; GUSMÃO FILHO, J.A. 1990. Carta Geotécnica da Cidade do Recife. In: CONGRESSO BRASILEIRO DE MECÂNICA DOS SOLOS E ENGENHARIA DE FUNDAÇÕES, 9ำ Porto Alegre, ABMS. Anais.v.1, p. 429-439.

FERREIRA, S.R.M.; AMORIM JR., W.; COUTINHO, R.Q. 1986, Argila orgânica do Recife: contribuição ao banco de dados. In: CONGRESSO BRASILEIRO DE MECÂNICA DOS SOLOS E ENGENHARIA DE FUNDAÇÕES, $8^{\circ}$, Porto Alegre, ABMS. Anais.v.1, p. 183-197.

GUSMÃO FILHO, J.A. 1982. Prática de fundações nas capitais nordestinas. In: CONGRESSO BRASILEIRO DE MECÂNICA DOS SOLOS E ENGENHARIA DE FUNDAÇÕES, 7º, Olinda/ Recife, ABMS. Anais.v.1, p. 189- 200.

1987. Controle de erosão nos morros do Recife. In: SIMPÓSIO NACIONAL DE CONTROLE DE EROSÃO, 4º, Marília, SP, ABGE. Anais, p. 313-329.

1990. Ação integrada contra riscos geológicos em morros urbanos. In: SIMPÓSIO LATINO-AMERICANO 
CONTRA RISCOS GEOLOGICOS URBANOS, 1ำ São Paulo, IAEG. Anais. p. 421-435.

1993. O risco geológico no Recife. In: CONGRESSO BRASILEIRO DE GEOLOGIA DE ENGENHARIA, 7을 Poços de Caldas, MG, ABGE. MesaRedonda sobre risco geológico, Anais. V. 3 (no prelo), $16 \mathrm{p}$.

FIGUEIREDO, L.C.; COSTA, W.D.; AMORIM JR., W.; JUSTINO DA SILVA, J.M. 1982. Caracterização geológico-geotécnica dos morros de Olinda. In: CONGRESSO BRASILEIRO DE MECÂNICA DOS SOLOS E ENGENHARIA DE FUNDAÇÕES, 7º, Olinda/Recife, ABMS. Anais.v.1, p. 75-102.

GUSMÃO FILHO, J.A.; COSTA, W.D.; FEITOSA, E. 1984. Estudo de encostas em áreas urbanas. In: CONGRESSO BRASILEIRO DE GEOLOGIA DE ENGENHARIA, 4으. Belo Horizonte, ABGE. Anais.v.2, p. 89-107.

GUSMÃO FILHO, J.A.; JUCÁ, J.F.T.; JUSTINO DA SILVA, J.M.; FERREIRA, S.R. 1986a. Parâmetros geomecânicos dos solos de Olinda. In: CONGRESSO BRASILEIRO DE MECÂNICA DOS SOLOS E ENGENHARIA DE FUNDAÇÕES, $8^{\circ}$, Porto Alegre, ABMS. Anais.v.1, p. 199-210.

GUSMÃO FILHO, J.A.; JUCÁ, J.F.T.; JUSTINO DA SILVA, J.M. 1986b. Mecanismo dos movimentos dos morros de Olinda. In: CONGRESSO BRASILEIRO DE MECÂNICA DOS SOLOS E ENGENHARIA DE FUNDAÇÕES, 8ㅜㅗ Porto Alegre, ABMS. Anais. v.3, p. 135- 149.

GUSMÃO FILHO, J.A.; JUCÁ, J.F.T.; JUSTINO DA SILVA, J.M., 1986c. The evolution of the relief and moving mechanisms involved in the hills of Olinda, Brazil. In: INTERNATIONAL CONGRESS OF
ENGINEERING GEOLOGY, 5, Buenos Aires, IAEG. Anais. v.3, p. 1893 a 1903.

GUSMÃO FILHO, J.A.; JUCÁ, J.F.T.; JUSTINO DA SILVA, J.M. 1987. Groundwater effects in the moving mechanisms in the hills of Olinda, Brazil. In: EUROPEAN CONFERENCE ON SOIL MECHANICS AND FOUNDATION ENGINEERING, 9, Dublin, Irlanda, ISSMFE. Proceedings. v.1, p. 431-434.

LIMA FILHO, M.F. \& ALHEIROS, M.M. 1990. Planície de Recife: origem e características geotécnicas. CIVIL 90, Recife, ITEP. Anais. v.2, p. 205-216.

MELO, L.V. \& MENEZES, M.F. 1987a. Considerações sobre os processos erosivos nos sedimentos da Formação Guararapes (Grupo Barreiras) no Recife. In: SIMPÓSIO NACIONAL DE CONTROLE DE EROSÃO, 4º, Marília, SP, ABGE. Anais. p. 179-196.

1987b. Erosão urbana nos sedimentos da Formação Riacho Morno, Grupo Barreiras. CONGRESSO BRASILEIRO DE GEOLOGIA DE ENGENHARIA, 5², São Paulo, ABGE. Anais. v.2.

1987c. Uma tentativa para definição das áreas de risco nos morros da cidade do Recife. In: SIMPOSIO LATINOAMERICANO SOBRE RISCO GEOLÓGICO URBANO, 1ำ São Paulo, ABGE. Anais. p. 281-292.

MENEZES, J.L.M. 1988. Atlas histórico e cartográfico do Recife. Ed. Massangana, Fundação Joaquim Nabuco, Recife. 110 p.

MENEZES, W.G. 1987. A pluviosidade e os escorregamentos de taludes na zona urbana do Recife. In: CONGRESSO BRASILEIRO DE GEOLOGIA DE ENGENHARIA, 5ำ, São Paulo, ABGE. Anais. v.2, p. 347-358. 